Article

\title{
Truffle species strongly shapes its surrounding soil mycobiota in a Pinus armandii forest
}

\author{
Dong Liu ${ }^{1 *}$, Mariana Herrera ${ }^{1}$, Xinhua $\mathrm{He}^{1,2}$, Jesús Perez-Moreno ${ }^{3}$, Fuqiang $\mathrm{Yu}^{1 *}$ \\ 1 The Germplasm Bank of Wild Species, Yunnan Key Laboratory for Fungal Diversity and Green \\ Development, Kunming Institute of Botany, Chinese Academy of Sciences, Kunming, Yunnan, 650201, \\ China; herrerac.mariana@gmail.com (M.H.) \\ 2 Department of Land, Air and Water Resources, University of California at Davis, Davis, CA 95616, USA; \\ xinhua.he@uwa.edu.au (X.H.H.) \\ 3 Colegio de Postgraduados, Campus Montecillo, Microbiología, Edafología, Texcoco, 56230, Mexico; \\ jepemo@yahoo.com.mx (J.P.-M.) \\ * Correspondence: liudongc@mail.kib.ac.cn (D.L.); fqyu@mail.kib.ac.cn (F.Q.Y.)
}

\begin{abstract}
Truffles contribute to crucial dynamics in the soil systems, being involved in plentiful ecological functions important for ecosystems. Despite this, the interactions between truffles and surrounding mycobiota remain unknown. Here, we aimed to shed light on how much truffle species could affect its surrounding soil mycobiota. Using traditional chemical analysis and Illumina ITS amplicon sequencing, we compared soil nutrients and mycobiota surrounding two truffle species: Tuber indicum (Ti) and T. pseudohimalayense (Tp) inhabit in the same Pinus armandii forest in southwestern China. Tp soil was more acidic and had higher nutrients (total C, N, P contents) than Ti soil. Fungal richness and diversity of truffle ascomata and surrounding soils were significantly higher in Tp than in Ti. Redundancy analysis showed relationships between soil fungal taxa and soil properties had changed from negative (Tp) to positive (Ti) and shifted from a moisture-driving (Tp) to a total N-driving (Ti). Overall, our results showed that the interactions between truffle and soil system had been altered with species variation, although the causative peculiarity of these associations needs to be further studied.
\end{abstract}

Keywords: hypogenous ectomycorrhizal fungi; truffles; soil nutrient; fungal community

\section{Introduction}

Truffles (Tuber spp.) are hypogenous ectomycorrhizal fungi that produce fruiting bodies with economic value representing one of the most expensive foods (edible wild fungi) worldwide [1]. Due to this, the interest for truffles has increased during the last two centuries being extensively studied in many topics specially the ones related with mycelia, species diversity, associations with host trees and soil biological quality [2-5]. During their life span, truffles inhabit in diverse and complex biotic environments, interacting as free mycelium, ascoma and/or mycorrhizal symbiont [6-8]. The development of truffles starts with a pellet of mycelium that gradually grows into a globular ascoma which the outward cells differentiate into a protective layer (peridium) with pores as authentic entryways $[9,10]$. Noticeably, during the process of maturation, the inhibition in herbaceous growth and reduction in biodiversity of soil fungal communities occurred [4,11], due to phytotoxic metabolites emitted by some truffle species (Tuber aestivum, T. melanosporum Vittad., and T. indicum Cooke \& Massee) [12-14] and allelopathy actions [15]. Competition among mycelia from different species for soil nutrients and water might possibly be the main ecological explanation for this 
phenomenon [16], and such competitive ability could vary among truffle species. Although studies regarding the bacterial diversity associated with truffle are highly available [17-19], the importance of the fungal communities in truffles and/or surrounding soil is usually ignored. In fact, the fungal communities have a close interaction with truffle peridium by colonizing through peridium pores to the gleba [1]. At present, the tripartite interactions between truffle species, soil property and fungal community in truffle soil are less studied. Regarding these interactions some questions arise to us: Will the soil properties and the composition of fungal communities in soil around ascomata vary between truffle species? If so, what are the main relationships between truffle taxa and soil properties? To understand how truffle species could affect its surrounding soil physicochemical properties, soil mycobiota, and their interactive relationships, two commercially important truffle species (Tuber indicum [20] and T. pseudohimalayense G. Moreno, Manjón, J. Díez \& García-Mont [22-23]) were examined by routine soil chemical analyses, ITS amplicon sequencing and redundancy analysis. These two ectomycorrhizal fungal species display similar morphology [22] and associate with the same Pinus armandii Franch. tree in southwest China [23]. This study addressed the following hypotheses: H1: the two fungal species could differentially affect the surrounding soil properties; H2: the fungal diversity and community structure could be different in truffle producing soils and ascomata; and H3: the driving factor of the relationship between fungal taxa and soil properties would be different at each truffle's niche.

\section{Materials and Methods}

\subsection{Study site and sampling strategy}

The sampling site is located in one of the Chinese truffle hotspots in Huidong county $\left(26^{\circ} 22^{\prime} 48^{\prime \prime} \mathrm{N}, 102^{\circ} 24^{\prime} 36^{\prime \prime} \mathrm{E}, 2745 \mathrm{~m}\right.$ a.s.1.) [20], Sichuan province, southwest China. The vegetation is a pure Pinus armandii Franch forest where the annual variation of air temperature ranged between $11 \sim 24^{\circ} \mathrm{C}$. The mean annual precipitation was $1099 \mathrm{~mm}$ [20]. The soil (Haplic Luvisol, FAO Soil Classification System) belongs to sandy loam [20]. Sampling of soil and truffles was carried out at the truffle producing period on December 2018. The ascomata and soil samples were collected from three plots (100 m away from each other) with an individual plot size of $200 \times 200 \mathrm{~m}$. A total of 9 soil and 12 fruiting body samples were examined in this study. Three composited (each had ten $0 \sim 10 \mathrm{~cm}$ soil cores with a sterile drill, $25 \mathrm{~cm}$ length and $5 \mathrm{~cm}$ diameter) soil samples in each plot were respectively collected from soil around and below the ascomata of $T$. indicum $\left(\mathrm{S}_{\mathrm{Ti}}\right), T$. pseudohimalayense $\left(\mathrm{S}_{\mathrm{T}}\right)$, and bulk or control soils $\left(\mathrm{S}_{\mathrm{c}}\right.$, ten meters away where no ascomata were detected). Soils were immediately stored in a cooler and transported to the laboratory where they were sieved $(2 \mathrm{~mm})$ to remove stone, root, and microfauna under aseptic conditions. Half of the obtained fresh samples were stored at $-20^{\circ} \mathrm{C}$ for microbial analysis and the rest soils were air-dried for chemical analyses.

Three composited fungal tissue samples (each having 18 cutting slices obtained with a sterilized scalpel from six fruiting bodies of $T$. indicum or $T$. pseudohimalayense) were also respectively collected from the gleba or peridium of $T$. indicum ( $\mathrm{G}_{\mathrm{Ti}}$ or $\mathrm{P}_{\mathrm{Ti}}$ ) and T. pseudohimalayense (Gтр or $\mathrm{P}_{\mathrm{Tp}}$ ). After clean with sterilized milli-Q water, the peridium and gleba tissues of six selected ascomata from each plot were sampled using a sterilized scalpel, composited and then stored in sterilized self-sealing bags $(60 \mathrm{~mm} \times 85 \mathrm{~mm})$ at $-20^{\circ} \mathrm{C}$ for subsequent DNA extraction.

\subsection{Soil property analysis}

Soil $\mathrm{pH}$ was determined in a soil and distilled water (1:2.5, W/V) mixture using a Delta $320 \mathrm{pH}$ meter (Mettler-Toledo Instruments, Shanghai, China). Soil moisture was gravimetrically measured by oven drying at $105{ }^{\circ} \mathrm{C}$ for $24 \mathrm{~h}$. Soil organic matter was determined with the potassium dichromate external heating method [24]. Soil total carbon (TC) and total nitrogen (TN) were measured with an elemental analyzer (Vario MAX C/N, Hanau, Germany) [25]. Determination of alkaline hydrolyzable $\mathrm{N}$, calcium $\left(\mathrm{Ca}^{2+}\right)$, and magnesium $\left(\mathrm{Mg}^{2+}\right)$ was based on the Chinese national standard method [26]. 


\subsection{DNA extraction and PCR amplification}

DNA from soil and truffle samples were extracted using the MoBioPower Soil DNA kit (12888) and the DNeasy Plant Mini Kit (Qiagen SA, Germany), respectively. The ascomata of Ti and Tp were identified by both the morphological and molecular techniques in the Kunming Institute of Botany, Chinese Academy of Sciences, Kunming, China. Polymerase chain reaction (PCR) were carried out following the previously described method [27]. Internal transcribed spacer 2 (ITS 2) was amplified for fungal community analyses, using the primers ITS5-1737F and ITS2-2043R [28,29]. PCR thermal cycling conditions were $94^{\circ} \mathrm{C}$ for $5 \mathrm{~min}$ (initial denaturation), 30 cycles of $30 \mathrm{~s}$ at $94^{\circ} \mathrm{C}, 52{ }^{\circ} \mathrm{C} 30 \mathrm{~s}, 72^{\circ}$ C $30 \mathrm{~s}$, with a final extension for $10 \mathrm{~min}$ at $72{ }^{\circ} \mathrm{C}$. Amplicons were extracted from $1 \%$ agarose gels and purified with the EZNA Gel Extraction Kit (Omega, Bio-Tech, New York, USA) according to the manufacturer's guidelines and quantified with PicoGreen using a FLUOstar Optima microplate reader (BMG Labtech, Jena, Germany).

\subsection{Illumina MiSeq sequencing and bioinformatics}

Purified amplicons were pair-end sequenced $2 \times 300$ on the Illumina MiSeq platform (MAGIGE, Guangdong, China) using the MiSeq Reagent Kit v2 (600-cycles-PE, MS-102-3003). Sequences were processed and quality-filtered using the QIIME (V1.9.1) pipeline. The 300-bp reads ends were truncated from the first site with low quality (average quality values $<20$ over a 10-bp sliding window. The $\geq 10 \mathrm{bp}$ that passed through quality screening overlapping sequences were assembled using the FLASH software (v1.2.11) [30]. The high-quality sequences were clustered into operational taxonomic units (OTUs) at a 97\% similarity cutoff. Raw sequence data were deposited in the NCBI under the accession number PRJNA649675. For species identification, we compared our sequence with the one deposited the UNITE database (for ITS, http://unite.ut.ee/index.php) using a confidence threshold $\geq 0.5$. The OTUs assigned to the same phylum, class, genus, and species level were grouped together based on their taxonomic affiliations.

\subsection{Data processing and statistical analysis}

Shannon index and the observed species were used to evaluate fungal diversity and richness in soils and ascomata, respectively. One-way analysis of variance (ANOVA) followed by Tukey HSD (at $P<0.05$ ) was used to compare significant differences in diversity indices and soil properties. Beta-diversity from the overall microbial communities between paired samples were determined using the UniFrac metric [31] in the MOTHUR program (http://www.mothur. org). Principal Coordinate Analysis (PCoA) was performed by the vegan package of $\mathrm{R}$ software based on the weighted Unifrac distance matrix, and the obtained coordinate points were plotted using the ggplot 2 package in R software. Analysis of similarity (Anosim), non-parametric multivariate analysis of variance (Adonis) using distance matrices, and a multi-response permutation procedure (Mrpp) were used to examine fungal community differences [32-34]. Redundancy analysis (RDA) was used to analyze the relationship between fungal communities and soil properties. RDA is advantageous of assessing the explanatory power of each defined variable by parsing out other terms as constraints to calculate its proportion of total variance [35].

\section{Results}

\subsection{Soil cation and nutrients show changes}

Soil moisture was similar among the three soil positions/treatments, no matter whether it surrounded the ascomata or not (Table 1). Soil $\mathrm{pH}$ values were closed to neutral with the highest and lowest soil $\mathrm{pH}$ in soils around and below the ascomata of T. indicum and the bulk soil, respectively (Table 1$)$. The concentrations of $\mathrm{Ca}^{2+}$ and $\mathrm{Mg}^{2+}$ were significantly higher $(P<0.05)$ in the truffle soil of Ti, compared to Tp and the bulk soil (Table 1). In contrast, the concentrations of soil organic matter, total carbon and total nitrogen were similar among the bulk soil, Ti soil and Tp soil 
(Table 1). Whereas, the C:N ratio and the alkaline hydrolysable nitrogen content were significantly higher $(P<0.05)$ in the truffle soil of Tp, compared to Ti soil (Table 1$)$.

Table 1. Soil physicochemical properties in the soils around the ascomata of Tuber indicum and Tuber pseudohimalyense.

\begin{tabular}{|c|c|c|c|c|c|c|c|c|c|}
\hline Treatment & $\begin{array}{c}\text { Moisture } \\
\text { (\%) }\end{array}$ & $\mathrm{pH}$ & $\begin{array}{c}\mathrm{Ca}^{2+} \\
\left(\mathrm{mg} \mathrm{kg}^{-1}\right)\end{array}$ & $\begin{array}{c}\mathrm{Mg}^{2+} \\
\left(\mathrm{mg} \mathrm{kg}^{-1}\right)\end{array}$ & $\begin{array}{c}\mathrm{OM} \\
\left(\mathrm{g} \mathrm{kg}^{-1}\right)\end{array}$ & $\begin{array}{c}\mathrm{TC} \\
\left(\mathrm{g} \mathrm{kg}^{-1}\right)\end{array}$ & $\begin{array}{c}\mathrm{TN} \\
\left(\mathrm{g} \mathrm{kg}^{-1}\right)\end{array}$ & $\begin{array}{l}\mathrm{C}: \mathrm{N} \\
\text { ratio }\end{array}$ & $\begin{array}{c}\mathrm{AN} \\
\left(\mathrm{mg} \mathrm{kg}^{-1}\right)\end{array}$ \\
\hline Sc & $28 \pm 3 a$ & $6.29 \pm 0.10 \mathrm{~b}$ & $3935 \pm 242 b$ & $627 \pm 36 \mathrm{~b}$ & $80 \pm 4 a$ & $46.3 \pm 2.2 \mathrm{a}$ & $3.64 \pm 0.06 \mathrm{a}$ & $12.7 \pm 0.4 b$ & $319 \pm 4 a$ \\
\hline $\mathrm{S}_{\mathrm{Ti}}$ & $29 \pm 1 a$ & $6.62 \pm 0.05 a$ & $6035 \pm 221 \mathrm{a}$ & $1116 \pm 75 a$ & $78 \pm 10 a$ & $45.1 \pm 6.8 \mathrm{a}$ & $3.68 \pm 0.22 \mathrm{a}$ & $12.2 \pm 0.3 b$ & $283 \pm 6 b$ \\
\hline $\mathrm{S}_{\mathrm{Tp}}$ & $30 \pm 2 \mathrm{a}$ & $6.42 \pm 0.06 \mathrm{ab}$ & $4421 \pm 303 b$ & $786 \pm 27 \mathrm{~b}$ & $88 \pm 3 a$ & $51.2 \pm 1.5 \mathrm{a}$ & $3.78 \pm 0.15 a$ & $13.6 \pm 0.2 \mathrm{a}$ & $316 \pm 5 a$ \\
\hline
\end{tabular}

Values (means $\pm \mathrm{SD}, n=3$ ) followed by different letters are significantly different at $P<0.05$ (ANOVA, Tukey HSD). Abbreviations: AN = alkaline hydrolysable nitrogen; $\mathrm{OM}=$ organic matter; $\mathrm{Sc}$ $=$ bulk or control soils (ten meters away where had no any truffle); $\mathrm{S}_{\mathrm{Ti}}=$ soils around and below the ascomata of T. indicum; $\mathrm{S}_{\mathrm{T}}=$ soils around and below the ascomata of T. pseudohimalayense; $\mathrm{TC}=$ total carbon; $\mathrm{TN}=$ total nitrogen.

\subsection{Fungal diversity exhibits significant changes}

About 138,854-652,726 clean reads were obtained per sample and the reads length varied from 250 to $438 \mathrm{bp}$, with an average of $343 \mathrm{bp}$ (Table S1). A range of 130,532-626,071 sequences from individual samples $($ mean $=317,012$ ) were obtained (Table S1). A total of $6,657,258$ high quality sequences from all samples, were represented for 10 phyla, 21 classes, 96 orders, 179 families, and 342 genera of fungi. The observed fungal species was around 200 and similar between Ti and Tp ascomata. The fungal community diversity was similar in the peridium and gleba as shown by the Shannon diversity index (considering both richness and evenness) (Figure 1). The soil fungal richness and diversity from the soil around truffle ascomata were significantly higher $(P<0.05)$ in Tp than in Ti (Figure 1). Similarly, the numbers of unique OTUs in the ascomata (peridium and gleba) and in the soil around truffle were all higher in Tp than in Ti (Figure 2).
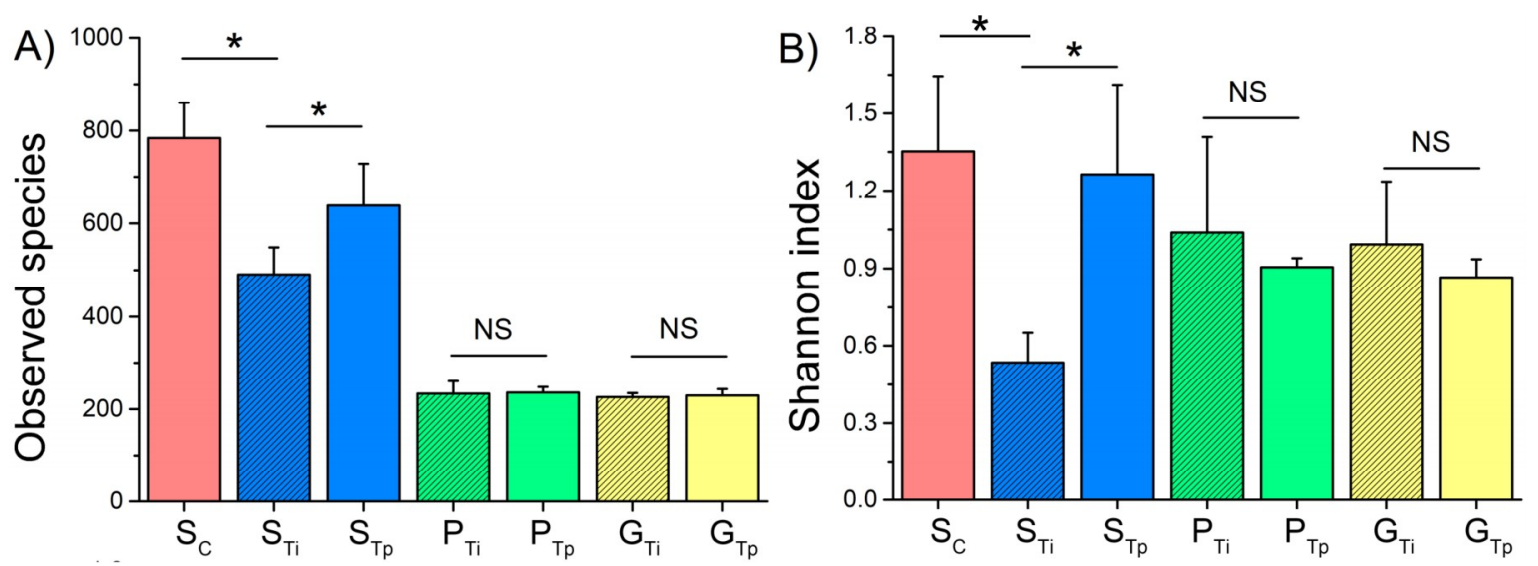

Figure 1. Fungal diversity indices in the control and truffle surrounding soils, and fungal tissues of Tuber indicum (Ti) and T. pseudohimalyense (Tp) occurring in a P. armandii forest in Huidong, Sichuan, southwest China. Alpha diversity indices were based on microbial richness (Observed species) and diversity (Shannon). For individual index boxes, differences among treatments were analyzed by post-hoc Tukey HSD test; ${ }^{*} P<0.05$. Abbreviations: $\mathrm{G}_{\mathrm{Ti}}=$ gleba of $T$. indicum; $\mathrm{G}_{\mathrm{Tp}}=$ gleba of $T$. pseudohimalyense; $\mathrm{P}_{\mathrm{Ti}}=$ peridium of $T$. indicum; $\mathrm{P}_{\mathrm{T}}=$ peridium of $T$. pseudohimalyense. $\mathrm{S} \mathrm{C}=$ control soils; $\mathrm{S}_{\mathrm{Ti}}=$ soils around and below the ascomata of $T$. indicum; $\mathrm{S}_{\mathrm{T}}=$ soils around and below the ascomata of T. pseudohimalayense. 


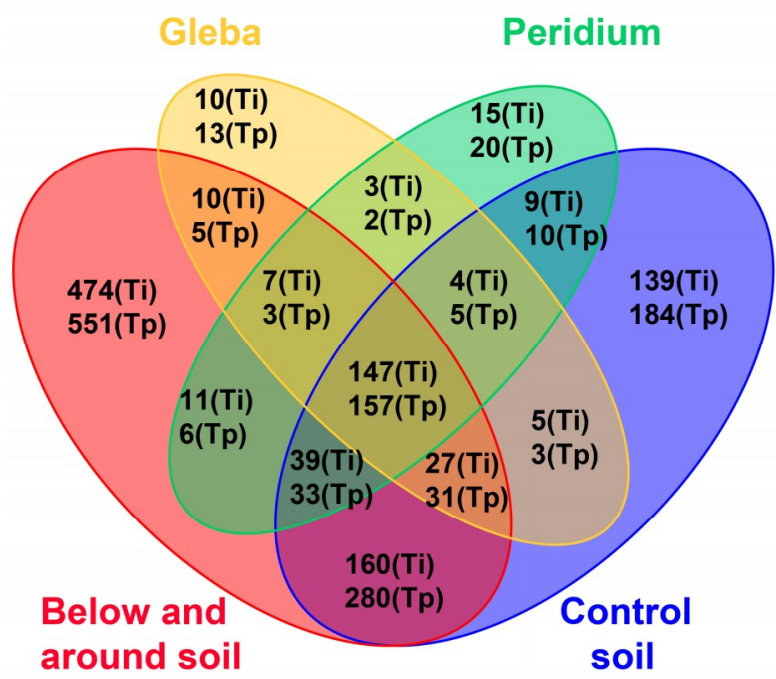

Figure 2. Shared and unique fungal OTUs in the control and truffle surrounding soils, and fungal tissues of Tuber indicum (Ti) and T. pseudohimalyense (Tp) occurring in a P. armandii forest in Huidong, Sichuan, southwest China. Abbreviations are shown in Figure 1.

\subsection{Distribution of fungal taxa and community structure}

The two-way cluster analysis of the relative abundance of major fungal genera showed a clear separation of two clusters in Ti and Tp surrounding soils, respectively (Figure 3). The fungal taxa of the truffle surrounding soil were clustered in different axes from truffle ascomata (Figure 3).
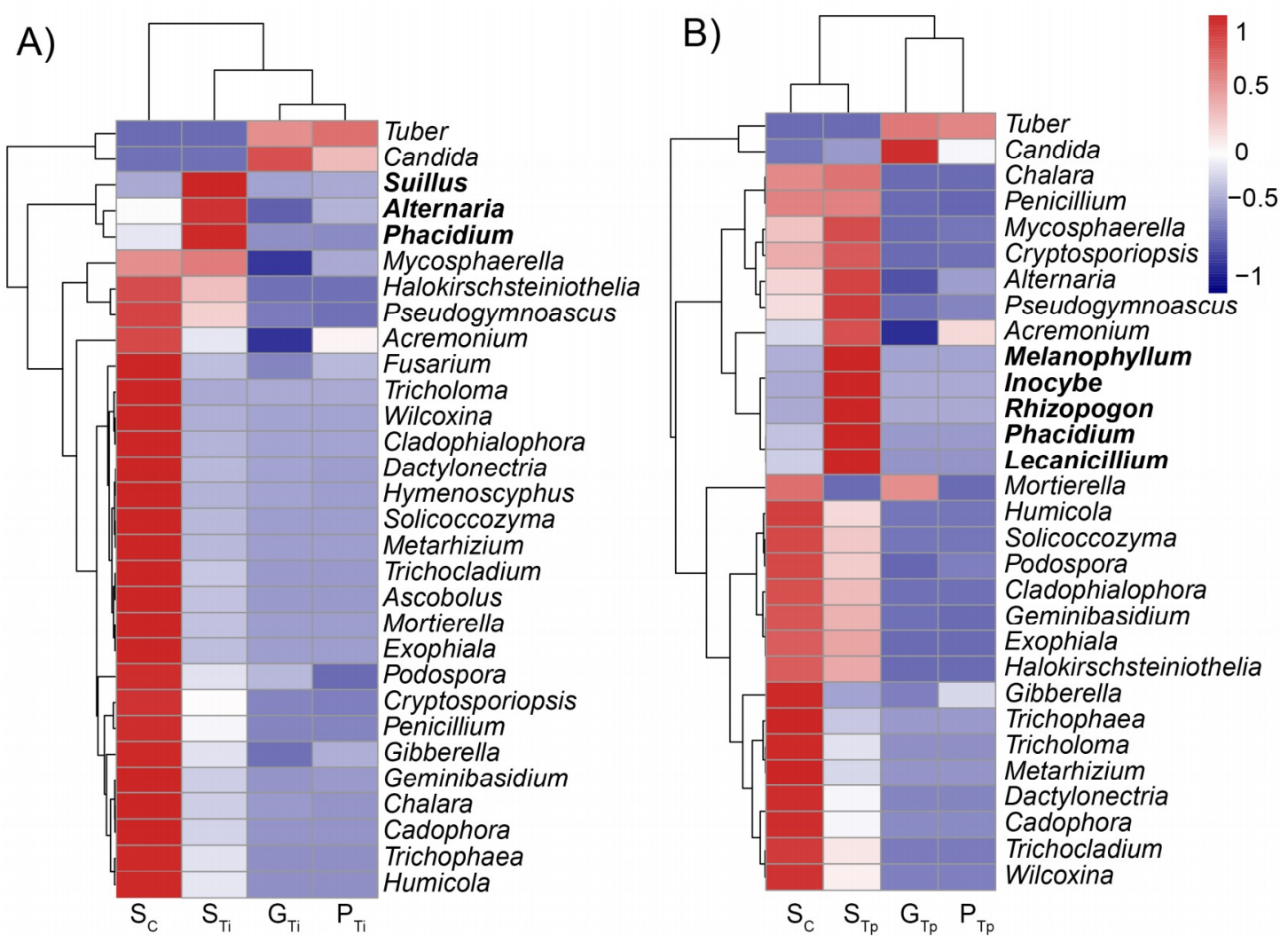

Figure 3. Heatmaps of the relative abundance of the top 30 fungal genera in the control and truffle surrounding soils, and fungal tissues of Tuber indicum (Ti) and T. pseudohimalyense (Tp) occurring in a $P$. armandii forest in Huidong, Sichuan, southwest China. The heatmap colors were the relative percentage of the fungal genera assignments with individual samples (presented as the mean of 
three bio-replicates). Square colors shifted towards represent higher abundance. Abbreviations are shown in Figure 1.

In $\mathrm{Ti}$ soil, six fungal taxa including Suillus, Alternaria, Phacidium, Mycosphaerella, Halokirschsteiniothelia, Pseudogymnoascus were dominant (reddish color) corresponding to species of Suillus, Alternaria and Phacidium (dark red). Over twenty fungal taxa were in the Tp soil where species of Melanophyllum, Inocybe, Rhizopogon, Rhacidium, and Lecanicillium showed higher abundances. The low fungal diversity of genera associated with the basidiomata, Candida in T. indicum and Candida, Acremonium, Mortierella in T. pseudohimalayense (Figure 3). Principal coordinates analysis (PCoA) showed that in the overall fungal community structures (beta-diversity) of the control and truffle soils were separated from those of truffle peridium and gleba (Figure 4). These results were statistically supported by the three dissimilarity tests including Adonis, Anosim and Mrpp $(P<0.05)$. The differences of fungal community structure between the truffle and their surrounding soil was stronger in Tp (ANOSIM test, $r=0.98, P=0.001$; Figure $4 \mathrm{~B}$ ) than in $\mathrm{Ti}$ (ANOSIM test, $\mathrm{r}=0.48, P=0.01$; Figure $4 \mathrm{~A}$ ). Such differences extended to truffle tissues (peridium and gleba). The truffle fungal community structure was significantly separated between Tp tissues (ANOSIM test, $\mathrm{R}=0.90, P=0.001$ ) but not between Ti tissues (ANOSIM test, $\mathrm{R}=0.18, P=0.16$ ).

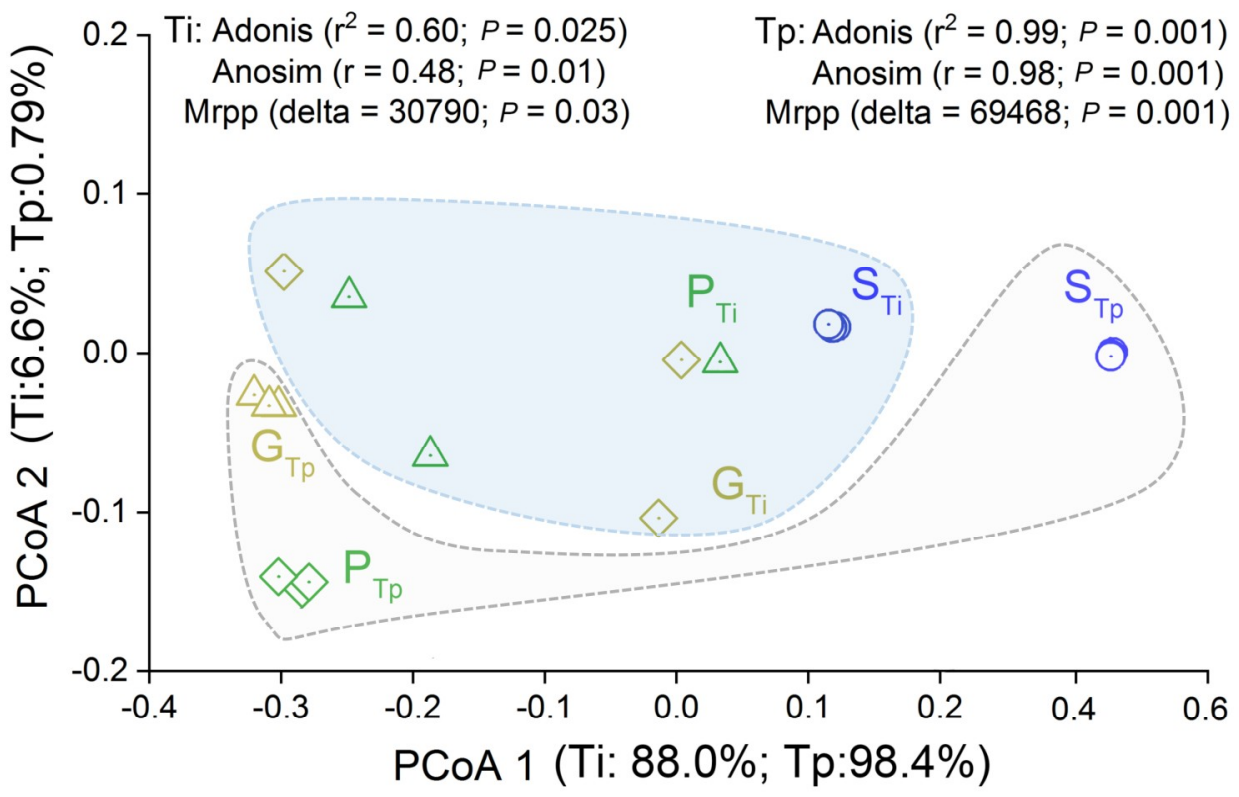

Figure 4. Fungal community compositions as indicated by principal coordinate analysis (PCoA) of pairwise Bray-Curtis distance in the truffle surrounding soils and fungal tissues of Tuber indicum (Ti) and T. pseudohimalyense (Tp) occurring in a P. armandii forest in Huidong, Sichuan, southwest China. Abbreviations are shown in Figure 1. Bray-Curtis distance-based results of three permutation dissimilarity tests were presented including analysis of similarity (Anosim), non-parametric multivariate analysis of variance (Adonis) using distance matrices, and a multiple response permutation procedure (Mrpp).

\subsection{Effects of soil properties on fungal communities show differences}

Redundancy analysis (RDA) showed relationships of the most influential soil properties and fungal genera in both $\mathrm{Ti}$ and $\mathrm{Tp}$ soil. For $\mathrm{Ti}$, the first and second axis of the RDA explained $92.7 \%$ and $7.3 \%$ variations in soil fungal taxa (Figure $5 \mathrm{~A}$ ). The variation in soil fungal taxa was strongly driven by total $\mathrm{N}$ with a contribution (explained fitted variation) $>90 \%$, and slightly driven by $\mathrm{pH}$ (7.5\%). Among the 30 top fungal taxa, almost all of them (except for Chalara) exhibited positive correlations with soil $\mathrm{pH}$ and total N. Species of Tuber, Rhizopogon, Inocybe, and Acremonium showed pronounced correlations as shown by their closer coordinate positions (Figure 5A) and was confirmed by significant positive correlations $(P<0.001$; Supplementary Figure 3$)$. In Tp soil, the first 
and second axis of the RDA explained among the $79.0 \%$ and $20.1 \%$ variations for fungal taxa (Figure $5 \mathrm{~B})$, mainly driven by soil moisture (78\% variation explained) and partly by total $\mathrm{N}$ ( $21 \%$ explained; Figure 5). Different from the change in $\mathrm{Ti}$, most fungal taxa in $\mathrm{Tp}$ surrounding soil exhibited negative correlations with the soil total $\mathrm{N}$ and moisture. There were only nine fungal taxa including Tuber which showed positive correlations, among them Lecanicillium, Wilcoxina and Trichiophaea were significant $(P<0.001$; Figure S2). In summary, with the consideration of the truffle species originated soil chemical changes, the total $\mathrm{N}$ and moisture were the major factors among soil properties that influence the soil fungal communities.
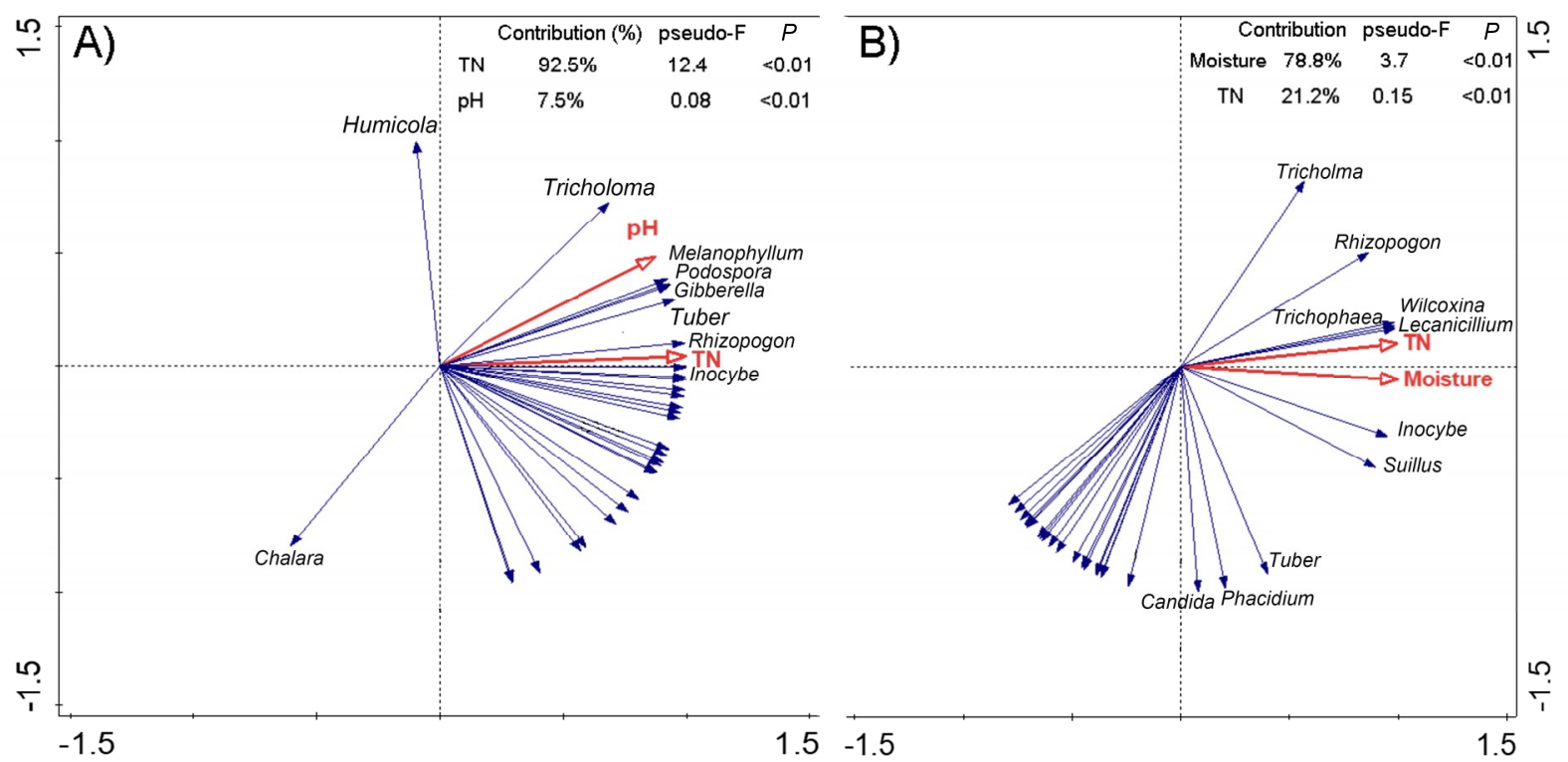

Figure 5. Redundancy analysis (RDA) showing the relationships of the most influential soil properties and fungal genera (Top 30) in the below and around soils of Tuber indicum (A) and T. pseudohimalyense (B) occurring in a P. armandii forest in Huidong, Sichuan, southwest China. The length of arrows represents the strength of the respective soil properties with the fungal genera. The angle between vectors indicates the degree of their associations (smaller angle means high correlation). To avoid the names of fungal genera overlapling, genera with loose assocations with soil major influencing factors were not showing alongaside the bule arrow, can be found in Fig. 3 .

\section{Discussion}

\subsection{Effect of truffle species on its surrounding soil properties}

As we hyphothezied (H1), the soil properties were affected by the truffle species showing different $\mathrm{Ca} 2+, \mathrm{Mg} 2+, \mathrm{C} / \mathrm{N}$ ratio in the truffles surrounding soils (Table 1). Tp seemed to require higher $\mathrm{Ca}^{2+}$ and $\mathrm{Mg}^{2+}$ to supply its ascomata development, as indicated by the significantly increased $\mathrm{Ca}^{2+}$ and $\mathrm{Mg}^{2+}$ concentrations in its surrounding soil as compared those of in Ti soil (Table 1). Similar results were reported by Hilzczanska (2018) [36] who mentioned that truffle abundance largely related to active carbonate content rather than soil $\mathrm{pH}$. Truffles can tolerate a wide range of soil $\mathrm{pH}$ from slightly acidic, neutral $[5,37,38]$ to alkaline [39]. We found Tp has formed in slight acidic soil $(\mathrm{pH}=6.4)$ in its surrounding as compared with $\mathrm{Ti}(\mathrm{pH}=6.6$; Table 1$)$. Noticeably, while the total $\mathrm{C}$ and $\mathrm{N}$ contents were not significantly affected by truffle species, the $\mathrm{C} / \mathrm{N}$ ratios were. The $\mathrm{C} / \mathrm{N}$ ratio in Tp soil was significantly higher, compared to Ti. It could be explained by higher biological activities (higher number of observed and unique fungal OTUs found in Tp soil; Figure 1 and 2) that could be involved in mineralizing more organic $\mathrm{N}$ than organic $\mathrm{C}$, with consequent variation in organic matter quality [5]. Also, the significantly higher hydrolysable $\mathrm{N}$ found in $\mathrm{Tp}$ than in $\mathrm{Ti}$ surrounding soil (Table 1) supported this argument. Admittedly, most of the tested soil parameters such as organic matter, total $\mathrm{N}$, total $\mathrm{C}$ shown variations, although not all significant, from soils around the two truffle species. From a field sampling experiment, a reliable explanation for the 
observed phenomenon was still weak. As result, pot experiments with Ti/Tp mycorrhiza seedings would monitor detailed dynamic of ion concentrations and soil available nutrients changes before and after truffle ascomata formation.

\subsection{Effects of truffle species on soil fungal communities}

We hypothesized that the truffle species would form its unique soil fungal community around its ascomata and the difference in fungal taxa might also exist in truffle tissues (H2). As expected, $\mathrm{Tp}$ surrounding soil exhibited significantly higher fungal richness and diversity, compared to Ti (Figure 1 ) and the change was in line with that in the soil $\mathrm{C} / \mathrm{N}$ ratio and TC contents ( $\mathrm{Tp}>\mathrm{Ti}$ ). The difference in the fungal diversity of the two truffle surrounding soils could relate to i) a closer association between soil fungi and nutrients such as TC, C/N ratio etc. [40,41]; ii) differences in truffle mycelia might trigger soil fungal diversity variation in truffle surrounding area since the truffle ascomata appeared only when certain amounts of mycelia formed [42]: the comparative ability of Ti mycelium could be stronger than that of $\mathrm{Tp}$, which might lead to a significant decrease in the diversity of soil mycobiota. It was admitted that the mycelial abundance from the two truffle species was not recorded in the present study, however in the two truffle soils, the changes in the number of dominant/abundant fungal taxa (21 in Tp vs. 6 in Ti), as well as the unique fungal OTUs (Figure 2 and 3) indirectly reflected various fungal competitive environments from surrounding soils.

When moving from control soil where truffles were not presented, fungal community tend to shift from Basidiomycota- to Ascomycota-dominated [43]. We found a relatively higher abundance of Ascomycota (65\%) in Tp soil, compared to Ti soil (25\%), which might reflect a stronger competition of $\mathrm{Tp}$ with other Basidiomycota [44]. Herein, we proposed a conceptual model to explain the effect of truffle species on its surrounding soil mycobiota and soil properties (Figure 6).

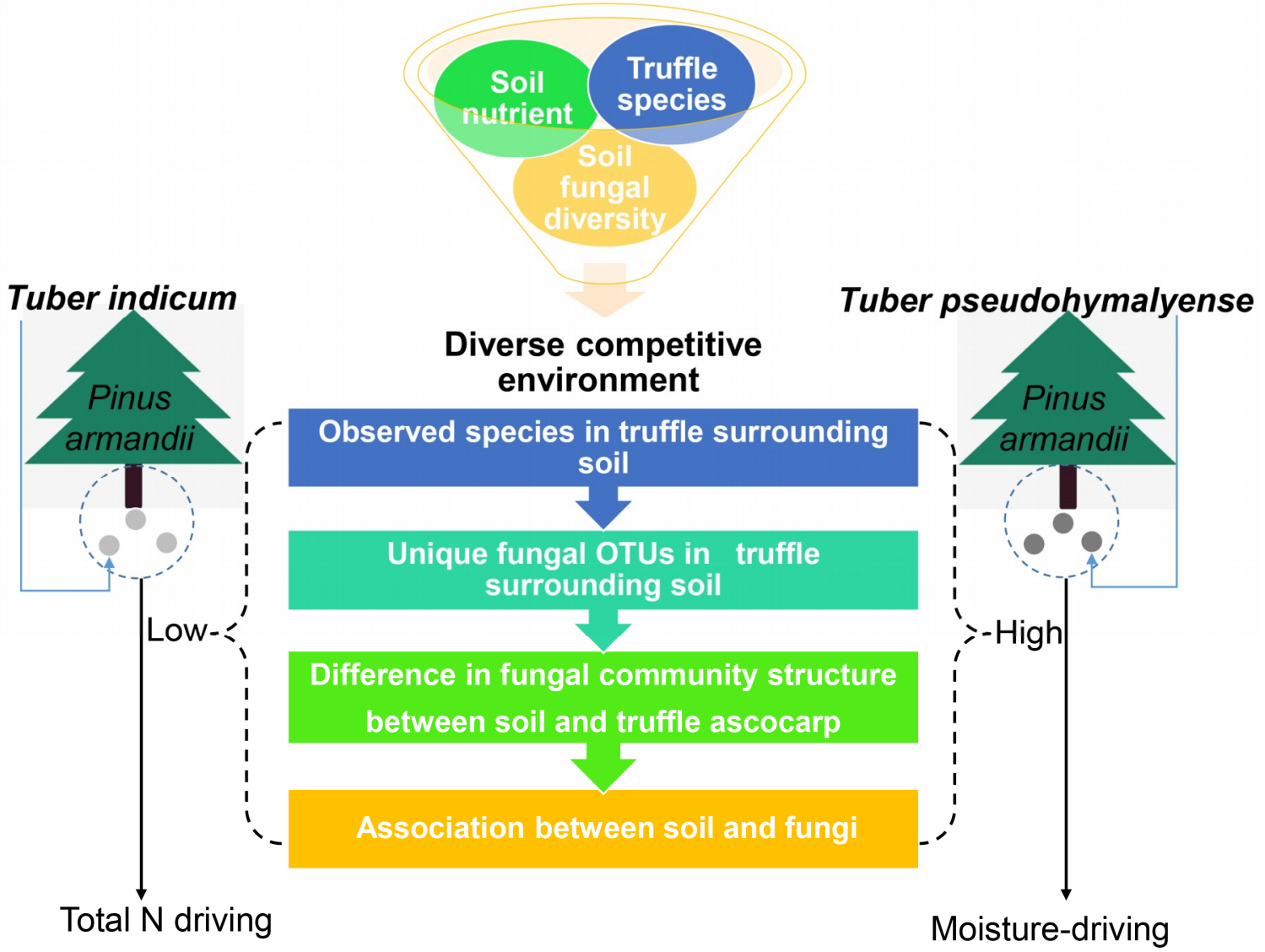

Figure 6. Diagram for the changes in the truffle surrounding soils and fungal tissues of Tuber indicum and $T$. pseudohimalyense occurring in a $P$. armandii forest. 
In support of the $\mathrm{H} 2$, changes in soil fungal community influenced truffle inhabiting fungi composition and structure (Figure 3 and 5). The changes in truffle surrounding soil properties and soil fungal diversity might induce further variations in the relationship between fungal taxa and soil properties (Figure 6). As we hypothesized (H3), major relationships between truffle surrounding fungal taxa and soil properties had changed from a total $\mathrm{N}$-driving (Ti) to a moisture-driving (Tp) (Figure 5 and 6), accompanying by a shift from negative (Ti) to positive (Tp) (Figure S1). The tripartite interactions between truffle species, soil nutrients and fungal diversity finally thus shaped a varied relationship between soil and fungi. It should be noted that the conceptual model we proposed (Figure 6) was based on the comparison between the two species within a similar habitat, which highlighted the important role from truffle itself. A systemic investigation in interactions between truffle and soil systems in further research is highly recommended, with consideration of multivariable properties such as soil texture, soil enzyme, and climatic factors.

\section{Conclusions}

Our results showed a clear difference in soil properties and fungal diversity from soils around the two truffle species (T. indicum and T. pseudohimalayense) in the same P. armandii forest. The presence of $T$. pseudohimalayense appeared to have a stronger influence to modify the soil environment, leading to changes in its chemistry (lower $\mathrm{pH}$ and higher nutrient contents). Soil nutrients, truffle species, and other soil fungal taxa are interactive. Such influences could form a complex and competitive environment in truffle unique ecological niches, and the effect might further extend to truffle tissues. The microbial community assembly in different truffle species inhabiting niches still needs to be explored to understand the interactions of hypogenous ectomycorrhizal fungi with soil systems.

Supplementary Materials: The following are available online at www.mdpi.com/xxx/s1

Author Contributions: Conceptualization, D.L. and J.P.M.; methodology, J.P.M. and F.Q.Y.; software, D.L.; validation, X.H.H.; formal analysis, D.L.; investigation, J.P.M. and F.Q.Y.; resources, F.Q.Y.; data curation, X.H.H.; writing - original draft preparation, D.L.; writing-review and editing, X.H.H. and M.H.; visualization, D.L.; supervision, D.L. and F.Q.Y.; project administration, D.L. and F.Q.Y.; funding acquisition, D.L. and F.Q.Y.

Funding: This research was funded by the CAS "Light of West China" Program. Science and Technology Service Network Initiative, Chinese Academy of Sciences (2017), and Guizhou Science and Technology Program (4002, 2018).

Acknowledgments: The authors are grateful to Shanping Wan comments for the first draft, to assistant engineer Peng Zhang and Ran Wang for invaluable assistance during mushroom collecting. We thank technicians in the elemental content analysis center, and Mr. Zhonghua Li for technical assistance in laboratory and data analyses.

Conflicts of Interest: The authors declare no conflict of interest. The funders had no role in the design of the study; in the collection, analyses, or interpretation of data; in the writing of the manuscript, or in the decision to publish the results.

\section{References}

1. Zambonelli, A. True Truffle (Tuber spp.) in the World; Zambonelli, A., Iotti, M., Murat, C., Eds.; Soil Biology; Springer International Publishing: Cham, 2016; Vol. 47; ISBN 978-3-319-31434-1.

2. Pacioni, G.; Leonardi, M.; Aimola, P.; Ragnelli, A.M.; Rubini, A.; Paolocci, F. Isolation and characterization of some mycelia inhabiting Tuber ascomata. Mycol. Res. 2007, 111, 1450-1460, doi:10.1016/j.mycres.2007.08.016.

3. Bonito, G.M.; Gryganskyi, A.P.; Trappe, J.M.; Vilgalys, R. A global meta-analysis of Tuber ITS rDNA sequences: Species diversity, host associations and long-distance dispersal. Mol. Ecol. 2010, 19, 4994-5008, doi:10.1111/j.1365-294X.2010.04855.x. 
4. Mello, A.; Lumini, E.; Napoli, C.; Bianciotto, V.; Bonfante, P. Arbuscular mycorrhizal fungal diversity in the Tuber melanosporum brûlé. Fungal Biol. 2015, 119, 518-527, doi:10.1016/j.funbio.2015.02.003.

5. Innangi, M.; Fioretto, A.; Fondón, C.L.; García-Montero, L.G.; Marzaioli, R.; Pinto, S.; Rutigliano, F.A.; Menta, C. Tuber aestivum is associated with changes in soil chemistry and reduced biological quality in a Quercus pubescens stand in Northern Italy. Pedobiologia (Jena). 2020, 80, 150648, doi:10.1016/j.pedobi.2020.150648.

6. Wenkart, S.; Roth-Bejerano, N.; Mills, D.; Kagan-Zur, V. Mycorrhizal associations between Tuber melanosporum mycelia and transformed roots of Cistus incanus. Plant Cell Rep. 2001, 20, 369-373, doi:10.1007/s002990100325.

7. Marozzi, G.; Sánchez, S.; Benucci, G.M.N.; Bonito, G.; Falini, L.B.; Albertini, E.; Donnini, D. Mycorrhization of pecan (Carya illinoinensis) with black truffles: Tuber melanosporum and Tuber brumale. Mycorrhiza 2017, 27, 303-309, doi:10.1007/s00572-016-0743-y.

8. Tang, Y.-J.; Liu, R.-S.; Li, H.-M. Current progress on truffle submerged fermentation: a promising alternative to its fruiting bodies. Appl. Microbiol. Biotechnol. 2015, 99, 2041-2053, doi:10.1007/s00253-015-6379-6.

9. Pacioni, G. Scanning electron microscopy of Tuber sporocarps and associated bacteria. Mycol. Res. 1990, 94, 1086-1089, doi:10.1016/S0953-7562(09)81338-5.

10. Zarivi, O.; Cesare, P.; Ragnelli, A.M.; Aimola, P.; Leonardi, M.; Bonfigli, A.; Colafarina, S.; Poma, A.M.; Miranda, M.; Pacioni, G. Validation of reference genes for quantitative real-time PCR in Périgord black truffle (Tuber melanosporum) developmental stages. Phytochemistry 2015, 116, 78-86, doi:10.1016/j.phytochem.2015.02.024.

11. De Miguel, A.M.; Águeda, B.; Sánchez, S.; Parladé, J. Ectomycorrhizal fungus diversity and community structure with natural and cultivated truffle hosts: applying lessons learned to future truffle culture. Mycorrhiza 2014, 24, 5-18, doi:10.1007/s00572-013-0554-3.

12. Pacioni, G.; Bellina-Agostinone, C.; D'Antonio, M. Odour composition of the Tuber melanosporum complex. Mycol. Res. 1990, 94, 201-204, doi:10.1016/S0953-7562(09)80614-X.

13. Pacioni, G.; Leonardi, M. Truffle-inhabiting fungi, in: True Truffle (Tuber spp.) in the World. In; Springer US, 2016; pp. 283-299.

14. Parladé, J.; De la Varga, H.; Pera, J. Tools to trace truffles in soil, in: True Truffle (Tuber spp.)in the World. In; 2016; pp. 249-266.

15. Streiblová, E.; Gryndlerová, H.; Gryndler, M. Truffle brûlé: an efficient fungal life strategy. FEMS Microbiol. Ecol. 2012, 80, 1-8, doi:10.1111/j.1574-6941.2011.01283.x.

16. Sourzat, P. Questions d'écologie appliquées à la trufficulture. Station d’Expérimentation Sur La Truffe. 2004.

17. Zampieri, E.; Chiapello, M.; Daghino, S.; Bonfante, P.; Mello, A. Soil metaproteomics reveals an inter-kingdom stress response to the presence of black truffles. Sci. Rep. 2016, 6, 25773, doi:10.1038/srep25773.

18. Mello, A.; Ding, G.-C.; Piceno, Y.M.; Napoli, C.; Tom, L.M.; DeSantis, T.Z.; Andersen, G.L.; Smalla, K.; Bonfante, P. Truffle brûlés have an impact on the diversity of soil bacterial communities. PLoS One 2013, 8 , e61945, doi:10.1371/journal.pone.0061945.

19. Barbieri, E.; Ceccaroli, P.; Agostini, D.; Zeppa, S.D.; Gioacchini, A.M.; Stocchi, V. Truffle-Associated Bacteria: Extrapolation from Diversity to Function. In True truffle (Tuber spp.) in the world soil ecology, systematics and biochemistry; Zambonelli, A., Iotti, M., Murat, C., Eds.; Springer US, 2016; pp. 301-317.

20. Fu, Y.; Li, X.; Li, Q.; Wu, H.; Xiong, C.; Geng, Q.; Sun, H.; Sun, Q. Soil microbial communities of three major Chinese truffles in southwest China. Can. J. Microbiol. 2016, 62, 970-979, doi:10.1139/cjm-2016-0139.

21. Moreno, G.; Manjón, J.L.; Díez, J.; García-Montero, L.G.; Di Massimo, G. Tuber pseudohimalayense sp. nov. an asiatic species commercialized in Spain, similar to the "perigord" truffle. Mycotaxon 1997, 63, 217-224.

22. Manjón, J.L.; García-Montero, L.G.; Pablo, A.; Gabriel, M.; Gabriella Di, M. Tuber pseudoexcavatum versus T. pseudohimalayense -new data on the molecular taxonomy and mycorrhizae of Chinese truffles. Mycotaxon 2009.

23. Juan, C.; Xiao, D.; Ji, C.; Peng, Q.; Jie, Z.; Shan, W.A.N. A Checklist of the Genus Tuber ( Pezizales , Ascomycota ) in China. J. Fungal Res. 2011, 9, 243-253.

24. Guo, M. Soil sampling and methods of analysis. J. Environ. Qual. 2009, 38, 375-375, doi:10.2134/jeq2008.0018br. 
25. Parkinson, J.A.; Allen, S.E. A wet oxidation procedure suitable for the determination of nitrogen and mineral nutrients in biological material. Commun. Soil Sci. Plant Anal. 1975, 6, 1-11, doi:10.1080/00103627509366539.

26. Nu, R.K. Soil agricultural chemical analysis; China Agricultural Science and Technology Press, 1999;

27. Xiong, W.; Zhao, Q.; Xue, C.; Xun, W.; Zhao, J.; Wu, H.; Li, R.; Shen, Q. Comparison of fungal community in black pepper-vanilla and vanilla monoculture systems associated with vanilla fusarium wilt disease. Front. Microbiol. 2016, 7, 117, doi:10.3389/fmicb.2016.00117.

28. Jeandroz, S.; Murat, C.; Wang, Y.; Bonfante, P.; Tacon, F. Le Molecular phylogeny and historical biogeography of the genus Tuber, the 'true truffles.' J. Biogeogr. 2008, 35, 815-829, doi:10.1111/j.1365-2699.2007.01851.x.

29. SCHULTZ, J. A common core of secondary structure of the internal transcribed spacer 2 (ITS2) throughout the Eukaryota. RNA 2005, 11, 361-364, doi:10.1261/rna.7204505.

30. Magoč, T.; Salzberg, S.L. FLASH: Fast length adjustment of short reads to improve genome assemblies. Bioinformatics 2011, 27, 2957-2963, doi:10.1093/bioinformatics/btr507.

31. Lozupone, C.; Lladser, M.E.; Knights, D.; Stombaugh, J.; Knight, R. UniFrac: An effective distance metric for microbial community comparison. ISME J. 2011, 5, 169-172.

32. Sickle, J. Van Using Mean Similarity Dendrograms to Evaluate Classifications. J. Agric. Biol. Environ. Stat. 1997, 2, 370, doi:10.2307/1400509.

33. CLARKE, K.R. Non-parametric multivariate analyses of changes in community structure. Austral Ecol. 1993, 18, 117-143, doi:10.1111/j.1442-9993.1993.tb00438.x.

34. Zapala, M.A.; Schork, N.J. Multivariate regression analysis of distance matrices for testing associations between gene expression patterns and related variables. Proc. Natl. Acad. Sci. 2006, 103, 19430-19435, doi:10.1073/pnas.0609333103.

35. O'Connor, R.J. Multivariate analysis of ecological communities. Trends Ecol. Evol. 1988, 3, 121, doi:10.1016/0169-5347(88)90124-3.

36. Hilszczańska, D.; Szmidla, H.; Sikora, K.; Rosa-Gruszecka, A. Soil Properties Conducive to the Formation of Tuber aestivum Vitt. Fruiting Bodies. Polish J. Environ. Stud. 2019, 28, 1713-1718, doi:10.15244/pjoes/89588.

37. Li, Q.; Zhao, J.; Xiong, C.; Li, X.; Chen, Z.; Li, P.; Huang, W. Tuber indicum shapes the microbial communities of ectomycorhizosphere soil and ectomycorrhizae of an indigenous tree (Pinus armandii). PLoS One 2017, 12, e0175720, doi:10.1371/journal.pone.0175720.

38. Li, Q.; Yan, L.; Ye, L.; Zhou, J.; Zhang, B.; Peng, W.; Zhang, X.; Li, X. Chinese Black Truffle (Tuber indicum) Alters the Ectomycorrhizosphere and Endoectomycosphere Microbiome and Metabolic Profiles of the Host Tree Quercus aliena. Front. Microbiol. 2018, 9, doi:10.3389/fmicb.2018.02202.

39. Mello, A.; Murat, C.; Bonfante, P. Truffles: much more than a prized and local fungal delicacy. FEMS Microbiol. Lett. 2006, 260, 1-8, doi:10.1111/j.1574-6968.2006.00252.x.

40. Liu, D.; Wang, H.; An, S.; Bhople, P.; Davlatbekov, F. Geographic distance and soil microbial biomass carbon drive biogeographical distribution of fungal communities in Chinese Loess Plateau soils. Sci. Total Environ. 2019, 660, 1058-1069, doi:10.1016/j.scitotenv.2019.01.097.

41. Yang, Y.; Cheng, H.; Dou, Y.; An, S. Plant and soil traits driving soil fungal community due to tree plantation on the Loess Plateau. Sci. Total Environ. 2020, 708, 134560, doi:10.1016/j.scitotenv.2019.134560.

42. Suz, L.M.; MartÃ-n, M.P.; Oliach, D.; Fischer, C.R.; Colinas, C. Mycelial abundance and other factors related to truffle productivity in Tuber melanosporum-Quercus ilex orchards. FEMS Microbiol. Lett. 2008, 285, 72-78, doi:10.1111/j.1574-6968.2008.01213.x.

43. Mello, A.; Napoli, C.; Murat, C.; Morin, E.; Marceddu, G.; Bonfante, P. ITS-1 versus ITS-2 pyrosequencing: a comparison of fungal populations in truffle grounds. Mycologia 2011, 103, 1184-1193, doi:10.3852/11-027.

44. Napoli, C.; Mello, A.; Borra, A.; Vizzini, A.; Sourzat, P.; Bonfante, P. Tuber melanosporum, when dominant, affects fungal dynamics in truffle grounds. New Phytol. 2010, 185, 237-247, doi:10.1111/j.1469-8137.2009.03053.x. 